\title{
The Role of Neighbourhood Social and Built Environments on Social Interactions and Community Wellbeing Through the COVID-19 Pandemic
}

\author{
Piret Veeroja and Greg Foliente
}

This chapter looks at the role of social and built environments on social interactions in Melbourne prior to, and during, the COVID-19 pandemic and discuss possible social and built environment interventions to increase social interactions. Melbournians have experienced two COVID-19 waves of infection and two lockdowns since March 2020 and faced severe physical and social distancing restrictions. These have increased the importance of local amenities and neighbourhoods, but also the need and skills to use telecommunication services for different social (and work related) purposes. Lockdown periods provide an opportunity to upskill peoples' technical skills that can be used after the pandemic to access more resources and create balance between online and face-to-face social environments. Possibilities in urban planning to repurpose the built environment and use technology to utilise local neighbourhoods are discussed. These proposed changes in social and built environments may be beneficial in dealing with future pandemics.

\subsection{Introduction}

Studies show that social interactions improve people's wellbeing, satisfaction with life [1], happiness [1], mental health [2], physical health [3], longevity [4] and reduce psychological distress such as anxiety $[5,6]$. Social interactions contribute to increased sense of purpose, belonging and self-worth $[2,7]$. These kinds of contributions motivate people and encourage them to take better care of themselves (e.g. to engage in physical activity or reduce alcohol intake) which lead to improved mental health [2]. Lack of social interactions, on the other hand, has been found to reduce quality of life, wellbeing, mood ([8,9] and health outcomes (such as insomnia, depression, dementia and suicide) and increase unhealthy behaviours (such as smoking, drinking alcohol, having unhealthy diet) [10].

As soon as the World Health Organisation (WHO) [11] announced that COVID-19 is a public health emergency of international concern, in response, many countries imposed restrictions such as social distancing, isolation and stay-at-home requirements. These types of restrictions may lead to loneliness and boredom [12]. Social isolation is opposite to social connectedness and has found to be related to psychological distress, such as anxiety $[6,13]$, depression, stress $[6,13]$ and loneliness [13]. Indeed, quarantine during the SARS outbreak in 2003 ([14], as cited in [13]) and the swine flu outbreak in 2009 ([15], as cited in [13]) was associated with increased depression and anxiety. Tull et al. [13] studied stay-at home restrictions and daily changed routines due to COVID-19 
pandemic with mental health outcomes $(n=500)$ in the United States. They concluded that the restrictions were associated with health related anxiety, financial worry and loneliness. Smith et al. [6] investigated the relationship between social isolation and mental health outcomes during COVID-19 pandemic $(n=278)$ in the Unites States. They found statistical relationships between the two and concluded that higher psychological flexibility and ability to accept difficult experiences helped to reduce the negative effects of social isolation [6].

Social capital, which is formed by strong and weak social networks, is found to be necessary in effective crisis response and recovery [16]. McCrea et al. [17] found that social and amenity dimensions were the main contributors of community wellbeing, that in turn, contributed towards community resilience. Communities with higher level of social capital, for example, were found to recover faster and in a more satisfactory and sustainable fashion from earthquakes than communities with lower social capital levels $[16,18]$.

This chapter aims to look at the role of social and built environments on social interactions in Melbourne prior to, and during, the COVID-19 pandemic and discuss about possible social and built environment interventions during and after the pandemic to increase social interactions. The discussions follow the main phases of COVID-19, as shown in Figure 6.1 for Victoria, Australia.

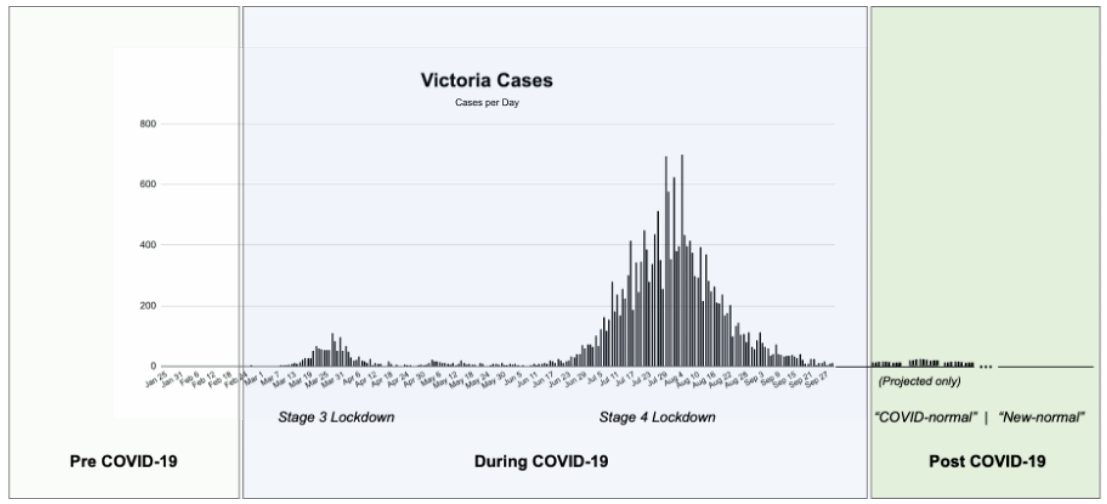

\section{FIGURE 6.1}

The Main Phases of COVID-19 Cases in the State of Victoria, Australia (Main data plot from: https://www.dhhs.vic.gov.au/victorian-coronavirus-covid-19-data)

\subsection{Pre COVID-19}

A previous study found that perceived social environment and especially feeling of belonging, sense of community and participation in community activities were more important to older Melbournians' (aged 55 years or above, $n=476$ ) local social interactions frequency than perceived and objective built environment measures [19]. Additionally, the importance of some types of perceived destinations for local social interactions were distinguished, such as cafes, bars and restaurants and footpaths. Looking at local social interaction satisfaction, the results were similar. Social interactions frequency, feeling of belonging and sense of community were social environment elements that contributed to older adults' local social interactions satisfaction. Perceived importance of local services for social interactions, however had a negative relationship with social interactions satisfaction [19].

Socioemotional selectivity theory explains that peoples' social networks are changing over time [20]. Younger people's social interactions are claimed to be future-oriented with the aim of gaining information, experiences and new social contacts [21]. Older people, on the other hand, have been found to prefer smaller, but emotionally meaningful and satisfying contacts [21]. It is thus 
expected that the importance of social and built environments in social interactions frequency and satisfaction is different in different age groups. Therefore, a follow up study that included younger, middle aged and older Melburnians were carried out. Surprisingly, the study reached similar conclusions across different age groups [22].

\subsection{During COVID-19}

\subsubsection{Social and Physical Distancing Restrictions in Melbourne}

The Victorian premier announced a State of Emergency in mid-March 2020, and on 30 March, Victoria entered a Stage 3 lockdown (see Figure 6.1). This meant that Victorians had only four reasons to leave home: shopping for food and supplies, (essential) work or education, exercising or caregiving. Restaurants, bars and coffees were allowed to be open for take-away only; beauty, personal services, entertainment, culture and sporting venues were closed. These restrictions started to ease in the beginning of June. Shortly after the ease of restrictions, the number of COVID-19 cases rose and in the beginning of August Victoria entered a Stage 4 lockdown (Figure 6.1). Additional social and physical distancing measures were introduced in this stage: curfew from 8PM-5AM (unless seeking or giving care or essential work), Victorians were allowed to shop (once a day, one person per household) and exercise one hour per day (maximum two people) in $5 \mathrm{~km}$ radius from their home. By the time of writing this chapter, Regional Victoria has entered to Stage 3 lockdown and some of the Stage 4 restrictions have eased for Metropolitan Melbourne (e.g. curfew is lifted) [23].

Previous studies have found that destinations (such as parks and nature strips, shops, services, cafes/bars/restaurants and community places) encourage peoples' local social interactions [24-26]. The Stage 3 and Stage 4 restrictions in Metropolitan Melbourne (and in the rest of the Victoria) have increased the importance of local destinations (especially after applying the five-km rule). People are more than ever dependent on their neighbourhoods and presence of local amenities. For instance, inhabitants who live in a close proximity to a park (or any other type of natural environment) or are able to access footpaths that are continuous and have even surface may be better off in terms of physical and mental health than those who are not able to access these types of amenities.

\subsubsection{Social Interactions During the Pandemic}

The COVID-19 pandemic may have adverse personal impacts, such as worrying about catching the virus, experiencing partial or full loss of income, worrying about job or housing security, uncertainty, home schooling, increased risk of family violence, and other mental, physical and social pressures caused by the lockdown and the resulting isolation. All these factors combined can lead to mental health crisis that in turn may lead to long-term problems in wellbeing, productivity and healthcare costs [27]. Social contact and support from family and friends and community are especially important in times like these. In May 2020, the United Nations (UN) warned that the COVID-19 might turn into mental health crisis [28] and reported an increase in levels of distress that causes misery due to the COVID-19 virus and emphasised the importance of the international community to support peoples' mental health during the pandemic [29]. A study of three cities in different countries in Latin America $(n=650)$ found that about one third of the participants missed face-to-face social interactions the most, when asked about the activities people miss due to the COVID-19 restrictions [30].

Fisher et al. [31] found that about a quarter of Australians experienced mild to moderate depressive symptoms or anxiety on the first month of COVID-19 restrictions. In 2020, there has been $66 \%$ increase in lifeline support calls compared to the previous year and two third of the calls were made by Victorians [32]. Alfred Hospital Crisis Assessment and Treatment Team have faced $50 \%$ increase in callouts after the first lockdown in March 2020 [33]. 
The Australian Government has provided an additional $\$ 500$ million in mental health and suicide prevention funding to assist in coping with the COVID-19 pandemic since January 2020. The Government provides several free-of-charge or low-cost telephone and telehealth services, such as Lifeline, Kids Helpline, Beyond Blue, Suicide Call-Back Service, MensLine Australia, Open Arms - Veterans and Families counselling, and HeadtoHealth services for Victorians. Citizens and permanent residents can access 10 additional subsidised psychological sessions to face mental issues caused by the pandemic. For older Australians, the Government has established the Older Persons COVID-19 Support Line (phone support) and Community Visitors Scheme (telephone or online). The latter connects older adults with volunteers who spend time with them during the pandemic; but face-to-face visits are replaced with telephone or online contacts [23].

Direct face-to-face social interactions and the use of neighbourhood social and built environments (and amenities) were minimised during the first lockdown and further restricted during the second lockdown in Melbourne (Figure 6.1). During the second lockdown, the majority of Melbournians were allowed to have face-to-face contacts with people from their own households (and other neighbourhood contacts such as when grocery shopping or ordering take-away coffee when adhering social and physical distancing rules). Therefore, the importance of virtual social environment was more important than ever before.

Telehealth services, however, can only be accessed when people have the ability and opportunity to use the technologies. The less skilled Internet users may become increasingly disconnected from the society and miss out on the digital support sources [34]. More than 2.5 million Australians are not online [35]. Digital inclusion requires access to high quality and affordable Internet service, hardware and sufficient data allowance, and ability and skills to use the technology. The Australian Digital Inclusion Index [36] shows, for example, that Australians with lower income, education, and employment levels; and adults aged 65 years or older are less digitally included [35]. Moreover, about 2.7 million (34\%) Australians aged 50 years or older have low digital skills or they don' $\mathrm{t}$ use the technology or the Internet [36]. More than half $(57 \%)$ of people aged 70 years or older have low digital skills and $74 \%$ of them do not use the Internet [36].

Gorenko et al. [37] recommended considering older adults' (and other socio-demographic groups) personal preferred remote communication methods and pre-pandemic technological literacy skills when providing interventions and improving technology using skills. These could include using technology that older adults are comfortable with (e.g. telephone), providing print materials with instructions, reminders and tips, and/or involving a household member or caretaker to explain/help to set up, use and/or troubleshoot the technology [37].

The internet, social media and other mobile applications are replacing traditional media and have both positive and negative effects [38]. The use of social media and the Internet may contribute to 'infodemic', which is information overload [12]. Banerjee and Rai [12] for example, describe COVID-19 as 'digital epidemic' where all sorts of information (including false information) about the virus travels faster than the virus itself. They recommend practicing social media distancing [12]. This means that while it is crucial to increase technical literacy in different age and demographic groups, then it is necessary to include information about where to find and how to control reliability of information/sources and understand the ethics or values underpinning specific artificial intelligence (AI) applications.

Another way to increase peoples' social interactions during the pandemic could be to set up virtual physical health programs that accommodate for different physical abilities and help people to stay active; provide online courses and classes; encourage volunteering in different programs $[36,39]$ or send out letters and greeting cards for those who are not technologically advanced $[36,39]$. Mariana Atkins and Baldassar [36] proposed to establish a buddy system where (older) adults can regularly check in and communicate with volunteers, or those with good technological literacy skills can help to set up and teach others' who are less skilled. This sort of volunteering enables people to feel they are helping others and may help to reduce their own feeling of isolation [39]. Office et al. [40], for example, investigated a phone outreach program ( $n=14$ volunteers, 25 calls) where medical students called to older Americans during the COVID-19 pandemic. The volunteers described the calls as impactful for the students and call recipients [40]. Community and religious groups could set up regular online/telephone meetings to share information and explain it, give health and mobility tips [36]. 
Gehl [41] observed changes in using public spaces during the pandemic in Denmark. They found that downtown activities were dropped, but the use of public spaces is similar as before the pandemic and places that offer activities (e.g. playgrounds) were used more than ever before [41]. This differs from the Melbourne context, because the use of public spaces (e.g. playgrounds, benches) was restricted. After easing some of the restrictions, small groups of people were allowed to have picnics in Melbourne. Inspired by the New York 'social distancing circles', similar circles were drawn on the grounds of some popular parks in Melbourne, so the groups who use the park are able to stay further than $1.5 \mathrm{~m}$ from other groups [42].

\subsection{Post COVID-19}

It is important to learn from the current pandemic and keep upskilling peoples' technological literacy and provide access to sufficient and affordable technology. This helps to ensure that people are able to access virtual social environment if the COVID-19 virus lingers on in the community or a similar situation occurs again in the future. Virtual social environment does not replace face-to-face community social interactions, but it may open an opportunity for members of society to be more effective, knowledgeable, resourceful and participatory in events that happen in physically distant locations. Some scholars propose that partially transforming to telehealth (e.g. mental and physical health issues, support group meetings for substance users, therapy sessions with councillors, outpatient programs, medication management programs) may be beneficial for patients and clinicians [27]. The future community social interactions may be a combination of face-to-face community social environment and virtual social environments (more accessible than it was before the pandemic). A future study could investigate the best ways to balance these modes of communication to ensure the best health and wellbeing outcomes.

Florida et al. [43] argued that historically, pandemics (e.g. Hispanic flue, plague) have always spread in cities (New York, London, Paris) and discussed about the ability of cities to bounce back after the virus. He argued that vulnerable people and families may be moving to suburbs, but cities will attract job seekers with higher number of jobs and salaries, and with more affordable rents than before the pandemic [43]. Joel Kotkin [43] added that cities may need to change crowded public transport with safer options (such as utilising autonomous vehicles), and it is critical to develop suburbs that produce lower emissions, provide working-from home opportunities, and lower commuting times. The provision of a metro-wide network of dedicated bicycle lanes has also attracted the attention/interest of many urban stakeholders.

The importance of the built physical environment may increase after the pandemic, and it might have a huge role to play in adjusting to the new 'COVID-19 normal' environment (Figure 6.1). Since the beginning of the pandemic, people have been asked to physically distance themselves from others. This means that urban planners need to think how to increase the amenities and infrastructure and decrease car-dependence [44]. Some urban planners and architects, however, see the opportunity in reduced use of city spaces due to COVID-19. This situation could be a turning point in how we use and think about cities. Jonathan et al. [45] see it as an opportunity to repurpose city streets for people to promote walking and cycling and create safe and attractive streets and cities or to convert street parking lots to places for street socialising. The restrictions have also further encouraged and strengthened discussions around 20-minute/15-minute cities. The concept has been proposed in Plan Melbourne [46]. These concepts refer to an idea that cities are polycentric and residents are able to access everything they need (e.g. employment, education, shopping, recreation) within 20 (or 15) minute walk, bike ride or via safe public transport from their home [47]. This sort of development, however, may mean more high-rise buildings in the areas, which may not be desirable in the future when planning for pandemic, as inhabitants would need to share lifts and common areas [48].

Chen et al. [49] propose that robotics (drones, driverless vehicles and service robots) and AI may be more useful than ever before. They concluded that facial-recognition software may offer new ways for aerial, ground and checkpoint territorial control, while admitting the possible problems 
with public safety, privacy and control [49]. Autonomous goods deliveries, drone transports, access to places via QR (or similar) codes and biometric screening to identify residents with high temperatures may be future solutions in urban environments if a similar pandemic occurs [49]. But these technologies require strong social acceptance and robust regulatory frameworks.

\subsection{Concluding Comments}

Social interactions with family, friends and the broader community are especially important for positive mental health outcomes, personal and community wellbeing during a pandemic. The use of social and built environments (and especially local destinations and amenities) have changed due to the COVID-19 pandemic. Telephone and Internet services are crucial to provide satisfying social environment, maintain social relationships with family, friends and community, and exchange information during these times. People with low income, education and employment levels and older adults, however, may not have enough means and/or skills to access these. Targeted or alternative solutions are needed, such as upskilling these societal groups to use the technology and provide affordable access to the Internet and technology during and post pandemic times. Finally, it is important to consider possibilities to repurpose and/or adapt existing built environment, better plan new ones and introduce more accessible technological innovations. Improved social and built environments may function as an opportunity for urban neighbourhood communities to recover faster via building local social capital and improved resilience when dealing with future pandemics.

\section{References}

[1] J. F. Helliwell and R. D. Putnam. The social context of well-being. Philosophical Transactions of the Royal Society of London Series B-Biological Sciences, 359(1449):1435-46, 2004. doi: 10.1098/rstb.2004.1522.

[2] Ichiro Kawachi and Lisa F Berkman. Social ties and mental health. Journal of Urban health, 78(3):458-467, 2001.

[3] Julia Sander, Jürgen Schupp, and David Richter. Getting together: Social contact frequency across the life span. Developmental Psychology, 53(8):1571, 2017.

[4] Eran Shor and David J Roelfs. Social contact frequency and all-cause mortality: A meta-analysis and meta-regression. Social Science \& Medicine, 128:76-86, 2015.

[5] L. Gibbs. Promoting resilience while preventing disease transmission: An Australian COVID-19 study. In A. Rajabifard, D. Páez, I. Britton, \& G. Foliente (Eds.), Pandemics Geospatial Information and Community Resilience. 2020.

[6] Brooke M Smith, Alexander J Twohy, and Gregory S Smith. Psychological inflexibility and intolerance of uncertainty moderate the relationship between social isolation and mental health outcomes during COVID-19. Journal of Contextual Behavioral Science, 2020. doi: https://doi.org/10.1016/j.jcbs.2020.09.005.

[7] Sheldon Cohen, Lynn G Underwood, and Benjamin H Gottlieb. Social support measurement and intervention: A guide for health and social scientists. Oxford University Press, 2000.

[8] J. T. Cacioppo, L. C. Hawkley, and R. A. Thisted. Perceived social isolation makes me sad: 5-year cross-lagged analyses of loneliness and depressive symptomatology in the Chicago Health, Aging, and Social Relations Study. Psychology and Aging, 25(2): 453-463. doi: 10.1037/a0017216.

[9] Jeannette Golden, Ronán M Conroy, Irene Bruce, Aisling Denihan, Elaine Greene, Michael Kirby, and Brian A Lawlor. Loneliness, social support networks, mood and wellbeing in community-dwelling elderly. International Journal of Geriatric Psychiatry, 24(7):694-700, 2009. doi: 10.1002/gps.2181.

[10] Kimberly A Van Orden, Emily Bower, Julie Lutz, Caroline Silva, Autumn M Gallegos, Carol A Podgorski, Elizabeth J Santos, and Yeates Conwell. Strategies to Promote Social Connections Among Older Adults During 'Social Distancing'Restrictions. The American Journal of Geriatric Psychiatry, 2020. doi: https: //doi.org/10.1016/j.jagp.2020.05.004. 
[11] World Health Organisation. WHO Director-General's statement on IHR Emergency Committee on Novel Coronavirus (2019-nCoV). 2020. URL https://www.who.int/dg/speeches/detail/who-director-general-sstatement-on-ihr-emergency-committee-on-novel-coronavirus-(2019-ncov).

[12] Debanjan Banerjee and Mayank Rai. Social isolation in Covid-19: The impact of loneliness. International Journal of Social Psychiatry, 66(6): 525-527, 2020. doi: 10.1177/0020764020922269.

[13] Matthew T Tull, Keith A Edmonds, Kayla Scamaldo, Julia R Richmond, Jason P Rose, and Kim L Gratz. Psychological outcomes associated with stay-at-home orders and the perceived impact of covid-19 on daily life. Psychiatry research, pages 289, 113098, 2020. doi: https://doi.org/10.1016/j.psychres.2020.113098.

[14] L. Hawryluck, W. L. Gold, S. Robinson, S. Pogorski, S. Galea, and R. Styra. SARS control and psychological effects of quarantine, Toronto, Canada. Emerging Infectious Diseases, 10(7): 1206-1212, 2004. doi: 10.3201/ eid1007.030703.

[15] Michael G Wheaton, Jonathan S Abramowitz, Noah C Berman, Laura E Fabricant, and Bunmi O Olatunji. Psychological predictors of anxiety in response to the H1N1 (swine flu) pandemic. Cognitive Therapy and Research, 36(3):210-218, 2012. doi: 10.1007/s10608-011-9353-3.

[16] Nicholas Pitas and Colin Ehmer. Social capital in the response to covid-19. American Journal of Health Promotion, 0(0), page 0890117120924531, 2020. doi: 10.1177/0890117120924531.

[17] R. McCrea, A. Walton, and R. Leonard. Developing a model of community wellbeing and resilience in response to change. Social Indicators Research, 129(1), 195-214, 2016.

[18] D. P. Aldrich. Building resilience: Social capital in post-disaster recovery. University of Chicago Press, 2012.

[19] P. Veeroja. The role of social and built environments in supporting older adults social interaction (Doctorial dissertation). The University of Melbourne, 2019.

[20] Laura L Carstensen, Derek M Isaacowitz, and Susan T Charles. Taking time seriously: A theory of socioemotional selectivity. American Psychologist, 54(3):165, 1999.

[21] Kevin B Wright and Brian R Patterson. Socioemotional selectivity theory and the macrodynamics of friendship: The role of friendship style and communication in friendship across the lifespan. Communication Research Reports, 23(3):163-170, 2006.

[22] P. Veeroja, G. Foliente, R. McCrea, H. Badland, C. Pettit, and J. Day. How neighbourhood social and built environments influence social interactions: Differences between life stages. In R.W. Marans, R. Stimson, \& N. Webster (Eds.), Handbook of Quality of Life Research: Place and Space Perspectives. Northampton, MA, USA (submitted, under review): Edward Elgar Publishing Inc.

[23] Department of Health and Human Services. Coronavirus (COVID-19) resources for the general public. 2020. URL https://www.health.gov.au/resources/collections/novel-coronavirus-2019-ncov-resources.

[24] Paula J Gardner. Natural neighborhood networks-Important social networks in the lives of older adults aging in place. Journal of aging studies, 25(3):263-271, 2011. doi: https://doi.org/10.1016/j.jaging.2011.03.007.

[25] Paul Hickman. "Third places" and social interaction in deprived neighbourhoods in Great Britain. Journal of Housing and the Built Environment, 28(2):221-236, 2013. doi: 10.1007/s10901-012-9306-5.

[26] H. J. Lee. Older adults third places and perceived social connectedness. (Doctor of Philosophy). Texas AESM University, 2015. URL http://oaktrust.library.tamu.edu/bitstream/handle/1969.1/155291/LEEDISSERTATION-2015. pdf? sequence $=1$.

[27] S. Noori and I. Rosenthal. Mental Health after COVID-19. In the wake of the pandemic, there will be an even greater need for help in the face of loss, isolation and trauma. Scientific American, 2020. URL https://www.scientificamerican.com/article/mental-health-after-covid-19/.

[28] United Nations. Policy Brief: COVID-19 and the Need for Action on Mental Health. 2020. URL https: //www.un.org/sites/un2.un.org/files/un_policy_brief-covid_and_mental_health_final.pdf.

[29] United Nations. N leads call to protect most vulnerable from mental health crisis during and after COVID-19. 2020. URL https://news.un.org/en/story/2020/05/1063882.

[30] R. Marino, E. Vargas, and M. Flores. Impacts of COVID-19 lockdown restrictions on housing and public space use and adaptation: Urban proximity, public health, and vulnerability in three Latin American cities. In A. Rajabifard, D. Páez, I. Britton, \& G. Foliente (Eds.), COVID - 19. Geospatial Information and Community Resilience. Taylor \& Francis Group, 2020.

[31] Jane RW Fisher, Thach Duc Tran, Karin Hammargerg, Jayagowri Sastry, Hau Nguyen, Heather Rowe, Sally Popplestone, Ruby Stocker, Claire Stubber, and Maggie Kirkman. Mental health of people in australia in the first month of covid-19 restrictions: a national survey. The Medical Journal of Australia, page 1, 2020.

[32] J. Blakkarly. With Melbourne under lockdown and the Victorian government announcing much-needed funding for mental health services, we asked your questions about what support is actually available. SBS News, 2020. URL https://www.sbs.com.au/news/we-put-your-questions-about-mental-health-supportduring-the-pandemic-to-the-experts. 
[33] J. Longbottom. On the frontline with a mental health emergency team as they respond to the dark reality of the coronavirus crisis. ABC News, 2020. URL https://www.abc.net.au/news/2020-07-05/coronavirus-mentalhealth-crisis-response-team-during-covid-19/12402370.

[34] Minh Hao Nguyen, Jonathan Gruber, Jaelle Fuchs, Will Marler, Amanda Hunsaker, and Eszter Hargittai. Changes in Digital Communication During the COVID-19 Global Pandemic: Implications for Digital Inequality and Future Research. Social Media+ Society, 6(3):2056305120948255, 2020. doi: 10.1177/ 2056305120948255.

[35] J. Barraket and C. Wilson. Digital inclusion and COVID-19. CSI Response, 2020. URL https://www.csi. edu.au/media/uploads/csi-covid_factsheet_digitalinclusion.pdf.

[36] L Atkins, \& Baldassar. COVID-19, social isolation and ageing. CSI Response. 2020. URL https://www.csi. edu.au/media/uploads/csi_fact_sheet_social_covid-19_social_isolation_and_ageing.pdf.

[37] Julie A Gorenko, Chelsea Moran, Michelle Flynn, Keith Dobson, and Candace Konnert. Social Isolation and Psychological Distress Among Older Adults Related to COVID-19: A Narrative Review of Remotely-Delivered Interventions and Recommendations. Journal of Applied Gerontology, page 0733464820958550, 2020. doi: $10.1177 / 0733464820958550$.

[38] Creighton Connolly, S Harris Ali, and Roger Keil. On the relationships between covid-19 and extended urbanization. Dialogues in Human Geography, 10(2):213-216, 2020. doi: 10.1177/2043820620934209.

[39] Annie T Chen, Shaoqing Ge, Susie Cho, Andrew K Teng, Frances Chu, George Demiris, and Oleg Zaslavsky. Reactions to covid-19, information and technology use, and social connectedness among older adults with pre-frailty and frailty. Geriatric nursing (New York, N.Y.), S0197-4572(0120)30245-30247, 2020. doi: $10.1016 /$ j.gerinurse.2020.08.001.

[40] Marissa S Rodenstein, Tazim S Merchant, Tricia Rae Pendergrast, Lee A Lindquist, et al. Reducing Social Isolation of Seniors during COVID-19 through Medical Student Telephone Contact. Journal of the American Medical Directors Association, 21(7):948-950, 2020. URL https://doi.org/10.1016/j.jamda.2020.06.003.

[41] J. Gehl. Public Space \& Public Life during COVID 19. 2020. URL https://covid19.gehlpeople.com/files/ report.pdf.

[42] R. Russo. Social circles have been drawn in this Melbourne park to help with social distancing. Timeout, 2020. URL https://ww.timeout.com/melbourne/news/social-circles-have-been-drawn-in-this-melbournepark-to-help-with-social-distancing-093020.

[43] R. Florida, E. Glaeser, M. M. Sharif, K. Bedi, T. J. Campanella, C. H. Chee, and J. . . . Sadik-Khan. How Life in Our Cities Will Look After the Coronavirus Pandemic. Foreign Policy, 2020. URL https: //foreignpolicy.com/2020/05/01/future-of-cities-urban-life-after-coronavirus-pandemic/.

[44] B. Michael, F. Geoffrey, H. Jim, S. Mike, T. Steve, C. Maxine, and P. . . Stephen. Growing Pains. The Crisis in Growth Area Planning. 2020. URL https://www.charter29.com/s/Charter-29-Report-200904-as-printedand-mailed.pdf.

[45] D. Jonathan, D. Kim, and S. Quentin. We can't let coronavirus kill our cities. Here's how we can save urban life. 2020. URL https://www.architectureanddesign.com.au/features/features-articles/we-can-tlet-coronavirus-kill-our-cities\#.

[46] Victoria State Government. Plan Melbourne 2017-2050. 2017. URL http://www.planmelbourne.vic.gov.au/.

[47] D. L. Boucher. Local Living, Rise of 20 Minute Cities Post-Covid. 2020. URL https://theurbandeveloper. com/articles/local-living-rise-of-20-minute-cities-post-covid.

[48] B. Hall. 'Generational catastrophe': How COVID-19 could reshape Melbourne. 2020. URL https://www.theage.com.au/national/victoria/generational-catastrophe-how-covid-19-could-reshapemelbourne-20200715-p55c7b.html.

[49] B. Chen, S. Marvin, and A. While. Containing COVID-19 in China: AI and the robotic restructuring of future cities. Dialogues in Human Geography, 10(2): 238-241, 2020. doi: 10.1177/2043820620934267. 